\title{
Embedded Electromechanical Impedance and Strain Sensors for Health Monitoring of a Concrete Bridge
}

\author{
Dansheng Wang, Junbing Zhang, and Hongping Zhu \\ School of Civil Engineering and Mechanics, Huazhong University of Science and Technology, Wuhan 430074, China \\ Correspondence should be addressed to Dansheng Wang; danshwang@hust.edu.cn
}

Received 25 November 2014; Revised 14 February 2015; Accepted 15 February 2015

Academic Editor: Vadim V. Silberschmidt

Copyright ( 2015 Dansheng Wang et al. This is an open access article distributed under the Creative Commons Attribution License, which permits unrestricted use, distribution, and reproduction in any medium, provided the original work is properly cited.

\begin{abstract}
Piezoelectric lead zirconate titanate (PZT) is one of the piezoelectric smart materials, which has direct and converse piezoelectric effects and can serve as an active electromechanical impedance (EMI) sensor. The design and fabrication processes of EMI sensors embedded into concrete structures are presented briefly. Subsequently, finite element modeling and modal analysis of a continuous rigid frame bridge are implemented by using ANSYS and MIDAS and validated by the field test results. Uppermost, a health monitoring technique by employing the embedded EMI and strain sensors is proposed in this paper. The technique is not based on any physical model and is sensitive to incipient structural changes for its high frequency characteristics. A practical study on health monitoring of the continuous rigid frame bridge is implemented based on the EMI and strain signatures. In this study, some EMI and strain sensors are embedded into the box-sectional girders. The electrical admittances of distributed EMI active sensors and the strains of concrete are measured when the bridge is under construction or in operation. Based on the electrical admittance and strain measurements, the health statuses of the continuous rigid frame bridge are monitored and evaluated successfully in the construction and operation stages using a root-mean-square deviation (RMSD) index.
\end{abstract}

\section{Introduction}

The performance of in-service structures, such as bridges, dams, and tunnels, can be affected by the degradation and damage resulting from severe environmental conditions and excessive loads. Health monitoring of reinforced concrete bridges and other large-scale civil infrastructures has received considerable attention in recent years. Many techniques for structural health monitoring (SHM) have been reported in literatures [1-4], based on either the global or the local interrogations. In global interrogation techniques, the structure is mostly subjected to low frequency excitations, and the first few natural frequencies and mode shapes are extracted to assess the location and the size of damage. The main limitation of these global techniques is that they are not very sensitive to the localized incipient damage. For practical applications, these techniques have not been proved to be effective in detecting incipient structural damage. Moreover, the low frequency measurement data are more prone to contamination by ambient vibration noise, which also happens to be in the low frequency range, typically less than $100 \mathrm{~Hz}$ [5].
In recent years, many researches have also proposed the SHM methods based on the local strain responses of structures using optical fiber sensors. Zhang et al. [6] presented a fiber optic sensing technology for strain monitoring of engineering materials and structures. The research program consisted of laboratory tests including thermal tests, tensile tests and flexural tests, and a field application on a concrete bridge deck (Joffre Bridge) reinforced partly with fiber reinforced polymers. Zhang et al. [7] used the fiber Bragg grating (FBG) and Brillouin optical time domain reflectometry to monitor a rehabilitated concrete bridge strengthened by external prestressing. Laflamme et al. [8] presented a sensing method for automatically localizing strain over large surfaces and discussed preliminary results from an application on a bridge located in Ames. The sensor consists of several soft capacitors arranged in a matrix form, which can be applied over large areas. More investigations and applications on SHM based on optical fiber strain sensing can be found in the references [9-11]. The main disadvantages of these methods based on optical fiber sensors are that optical fibers need to 
be placed along the full-length structure and they are frail and damageable when embedded into concrete structures. The other local interrogation methods called nondestructive evaluation (NDE) methods have been investigated, such as the ultrasonic technology, acoustic emission, X-ray, impactecho, and visual inspections. In general, when these NDE methods are utilized, it is required that the structure is out of operation and the tested structural component is accessible [12], so they are not good choices for real-time and in-service structural health monitoring.

Piezoelectric ceramics (PZT) is one of the smart materials, which has direct and converse piezoelectric effects and can be used as EMI transducer. The EMI transducer can be easily surface bonded to or embedded into host structures and act as both sensors and actuators widely used in structural health monitoring because they are lightweight, robust, inexpensive, and high bandwidth. Over the last decade, a large number of studies on SHM using EMI transducers have been carried out [13-20]. In recent years, the EMIbased health monitoring method has provided a promising approach for health monitoring of large-scale structures. Kim et al. [21] proposed a vibration-impedance-based monitoring method to predict the loss of prestressing forces in prestressed concrete (PSC) girder bridges by using acceleration responses and electromechanical impedances. Hong et al. [22] proposed a hybrid damage monitoring scheme using parallel acceleration-impedance approaches to detect girder damage and support damage in steel plate-girder bridges which are under ambient train-induced excitations. Song et al. [23] developed a new EMI measurement technique specifically for continuous monitoring of large structures. Then, a series of experiments were carried out on a laboratory-size specimen and a full-scale bridge and building structures. The experimental results revealed that the proposed technique successfully measured the EMI signals from massive structures with a high signal-to-noise ratio (SNR) and good repeatability even when the conventional techniques failed to do so. However, in most of these investigations, the PZT patches were directly attached to the surface of the structures and used as EMI transducers for health monitoring, and most of the works were performed under the condition of laboratory. So far, no practical application of the EMI-based method using embedded impedance sensors to monitor the integration of large-scale concrete bridge structures has been reported.

This paper presents a practical study on health monitoring of a continuous rigid-frame bridge using finite element and EMI-based methods. Some EMI active sensors are designed and embedded into concrete at the critical sections of the box-sectional girders. The electrical admittances (inverse of impedance) of distributed EMI active sensors are measured when the bridge is constructing or suffering from operational loads. For comparison and cooperation, strain gauges are also arranged in adjacent regions of EMI sensors to obtain strains of concrete around them. It is found that the health statuses of the continuous rigid-frame bridge in construction and operation process are monitored and evaluated successfully based on the obtained real admittance and strain measurements.

\section{EMI-Based Health Monitoring Method}

A PZT patch produces an electrical charge when the mechanical stress is applied on, which is called the direct piezoelectric effect of PZT. Conversely, when an electrical field is applied on a PZT patch, a mechanical strain will be produced, which is called the converse piezoelectric effect of PZT. For a linear piezoelectric material, the relation between the electrical and mechanical variables can be described by the linear relations [24]:

$$
\begin{gathered}
S_{i}=s_{i j}^{E} T_{j}+d_{m i} E_{m}, \\
D_{m}=d_{m i} T_{i}+\varepsilon_{m k}^{T} E_{k},
\end{gathered}
$$

where $S$ is mechanical strain, $T$ is mechanical stress, $E$ is electric field, $D$ is charge density, $s$ is mechanical compliance, $d$ is piezoelectric strain constant, $\varepsilon$ is permittivity, and the subscripts $i, j, m$, and $k$ indicate the direction of stress, strain, and electric field. The superscripts $T$ and $E$ indicate that quantities are measured at zero stress and constant electric field, respectively. The first part of (1) describes the converse piezoelectric effect and the second part describes the direct piezoelectric effect.

The basic principle of EMI-based health monitoring method is to monitor the structural changes by measuring the electrical impedances of the EMI active sensors bonded onto or embedded into the structures. The electrical admittance $Y(\omega)$ of the EMI active sensor is a combined function of the mechanical impedance of the EMI sensor $Z_{a}(\omega)$ and that of the host structure $Z_{s}(\omega)$

$$
Y(\omega)=j \omega a\left[\bar{\varepsilon}_{33}^{T}(1-j \delta)-\frac{Z_{s}(\omega)}{Z_{s}(\omega)+Z_{a}(\omega)} d_{31}^{2} \bar{Y}_{11}^{E}\right],
$$

where $d_{31}, \bar{Y}_{11}^{E}$, and $\bar{\varepsilon}_{33}^{T}$ are the piezoelectric coupling constant, Young's modulus, and the complex dielectric constant of the PZT at zero stress, respectively; $a$ is a geometric constant of the PZT and $\delta$ is the dielectric loss tangent of the PZT. The equation indicates that the electrical admittance of the PZT bonded to or embedded into the structures is directly related to the mechanical impedance of a host structure.

Liang et al. [25] first proposed the electromechanical coupling property of piezoelectric materials and host structures and EMI technique. In their literature, the PZT transducer is attached on the surface of the structure by a high-strength adhesive which can be described as a simple one-dimensional model. Assuming that all the parameters of PZT are constant over the period of monitoring, the electrical admittance of the PZT is uniquely determined by the mechanical impedance of the host structure. Therefore, any change in the electrical admittance signature is considered as an indication of a change in the structural integrity. Through monitoring the measured electrical admittance signatures and comparing it to the pristine state signatures, the structural conditions can be identified qualitatively.

Contrary to the global interrogation techniques, high frequencies in the orders of a few $\mathrm{kHz}$ to a few hundred $\mathrm{kHz}$ are used in the EMI-based method. Under this high 


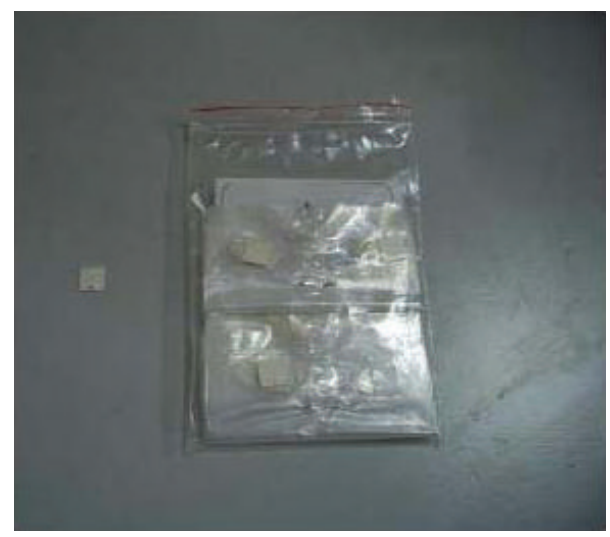

FIGURE 1: Naked PZT patches.

frequency range, the wavelength of the excitation is small and so sensitive enough to detect minor changes in the structural integrity. Due to the high frequency characteristics, the sensing region of the EMI transducer is limited to its close vicinity. Therefore, the EMI transducer is less sensitive to boundary condition changes or any operational vibrations. Because of these characteristics, the EMI-based technique has been considered as a robust, nondisturbing, and localsensitivity structural health monitoring technique.

\section{Design of Embedded EMI Active Sensors}

3.1. Waterproof of PZT Patches. The naked PZT5 type PZT patches with the dimensions of $8 \mathrm{~mm} \times 8 \mathrm{~mm} \times 0.3 \mathrm{~mm}$ are used to fabricate the embedded EMI active sensors, as shown in Figure 1. In the study, asphalt lacquer is used as the waterproof material. The waterproof process is as follows. First, both the surfaces of each naked PZT patch are welded to wires, respectively, and the bare PZT impedance sensors are formed. Second, the bare PZT impedance sensors are overlaid by asphalt lacquers, and a set of waterproofed PZT impedance sensors are shown in Figure 2. After the covered layer of PZT impedance sensors was solidified, we measured the electric admittances of the covered PZT impedance sensors for seven days. The real admittance measurements were shown in Figure 3. From Figure 3, it is found that in the seven days the real admittance curves of the PZT impedance sensors overlaid by asphalt lacquer hardly change. This indicates that the waterproof effect of asphalt lacquer is good and the PZT impedance sensors overlaid by asphalt lacquer are stable.

3.2. Encapsulation of EMI Impedance Sensors. In order to be applicable to health monitoring of concrete structures, the PZT impedance sensors are attempted to be encapsulated by Portland cements. The roles of encapsulation layer include the following: first, strengthen the waterproof capacity of PZT impedance sensors, second, keep PZT impedance sensors from breakage under construction, and third let the cement material be compatible to concrete structures, which makes good integration and stress transfer between sensors and concrete structures. Therefore, the PZT impedance sensors

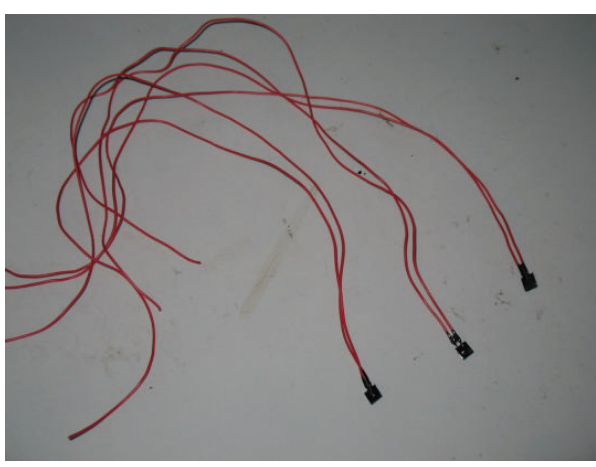

FIGURE 2: PZT impedance sensors covered with asphalt lacquer.

are encapsulated by using cement material after they are waterproofed by using asphalt lacquer and fully stable, as shown in Figure 4. So, the design and fabrication of the embedded EMI active sensors are finished.

After the encapsulation layer of EMI sensors was solidified fully, we measured the electric admittances of the encapsulated EMI active sensors for 34 days. The real admittance measurements in 28-34 days were shown in Figure 5. From Figure 5, it is found that in the seven days the real admittance curves of the EMI sensors encapsulated by Portland cements hardly change. This indicates that the encapsulation effect of Portland cements is good and the EMI active sensors encapsulated by Portland cements are basically stable, which can be used to monitor the concrete structures.

\section{Health Monitoring of a Continuous Rigid-Frame Bridge}

A large-span prestressed continuous rigid-frame box bridge is investigated for health monitoring in this paper. The span of this bridge is $58 \mathrm{~m}+90 \mathrm{~m}+58 \mathrm{~m}$. The bridge deck is bidirectional and four lane pavements with a width of $13.5 \mathrm{~m}$. A layout of the bridge is shown in Figure 6.

4.1. Dynamic Property Analysis by Using Finite Element Method. Finite element modeling and analysis are implemented here by using commercial software programs: ANSYS and MIDAS. Their main aim is to determine the optimal acceleration sensors and their arrangements for modal test on site. In addition, they will also provide more supports for future condition evaluation of the rigid-frame box bridge. The material parameters of concrete piers and prestressed concrete box girders are listed in Tables 1 and 2, respectively. When establishing the finite element model of the bridge by using ANSYS, the concrete is modeled by the use of SOLID65 element, which is 8-node hexahedron element and can simulate the actual deformation of RC effectively. The steel bar is simulated by using LINK8 element, and the secondary dead loads, such as the rigid layer of the bridge deck pavement, are simulated by using MASS21 element. When modeling, the sizes of finite element meshes are restrained to less than $0.45 \mathrm{~m}$ in general and restrained to $0.25 \mathrm{~m}$ in local area. The whole finite element model of 
TABLE 1: Material parameters of concrete piers.

\begin{tabular}{lcccc}
\hline Material types & Density $\rho\left(\mathrm{kg} / \mathrm{m}^{3}\right)$ & Modulus of elasticity $E(\mathrm{MPa})$ & Compressive strength $(\mathrm{MPa})$ & Tensile strength $(\mathrm{MPa})$ \\
\hline Concrete & 2500 & $3.25 \times 10^{4}$ & 22.4 & 1.65 \\
Rebar & 7850 & $2.0 \times 10^{5}$ & 300 & 300 \\
\hline
\end{tabular}

TABLE 2: Material parameters of prestressed concrete box girders.

\begin{tabular}{lcccc}
\hline Material types & Density $\rho\left(\mathrm{kg} / \mathrm{m}^{3}\right)$ & Modulus of elasticity $E(\mathrm{MPa})$ & Compressive strength $(\mathrm{MPa})$ & Tensile strength $(\mathrm{MPa})$ \\
\hline Concrete & 2600 & $3.45 \times 10^{4}$ & 22.4 & 1.65 \\
Rebar & 7850 & $2.0 \times 10^{5}$ & 300 & 300 \\
Steel strand & 7850 & $1.95 \times 10^{5}$ & 390 & 1320 \\
\hline
\end{tabular}

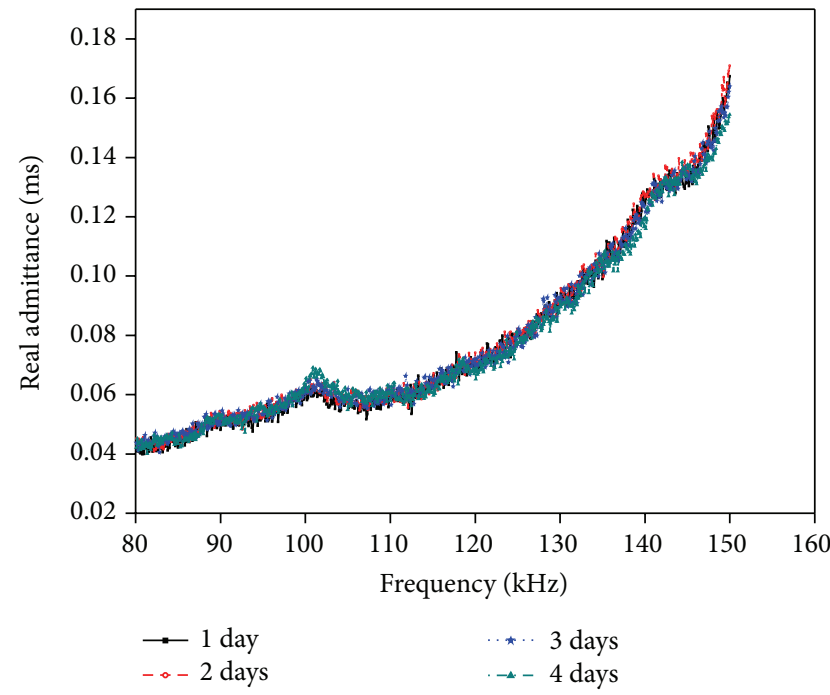

(a)

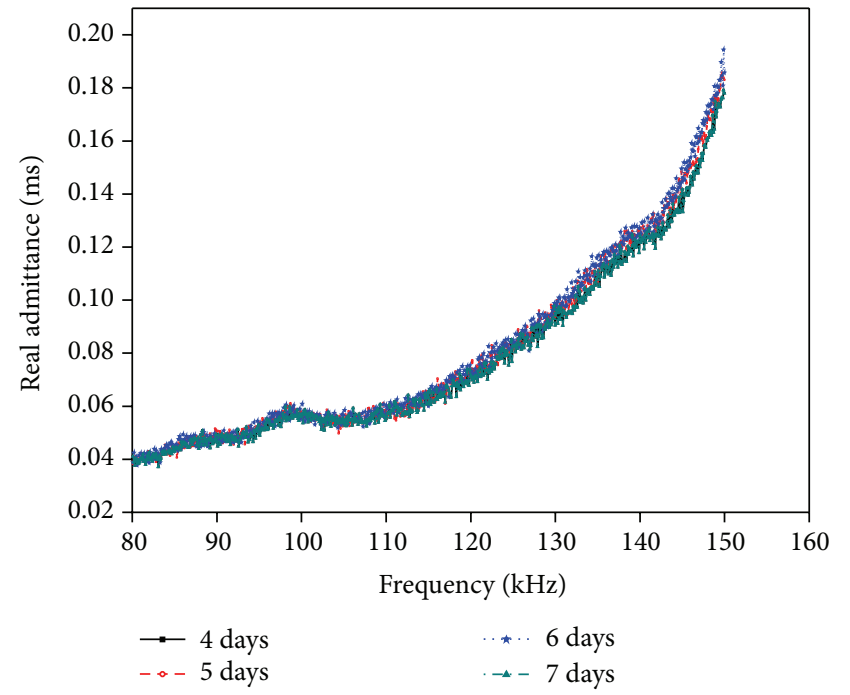

(b)

FIGURE 3: Real admittances of the PZT impedance sensors waterproofed by asphalt lacquer: (a) 1-4 days and (b) 4-7 days.

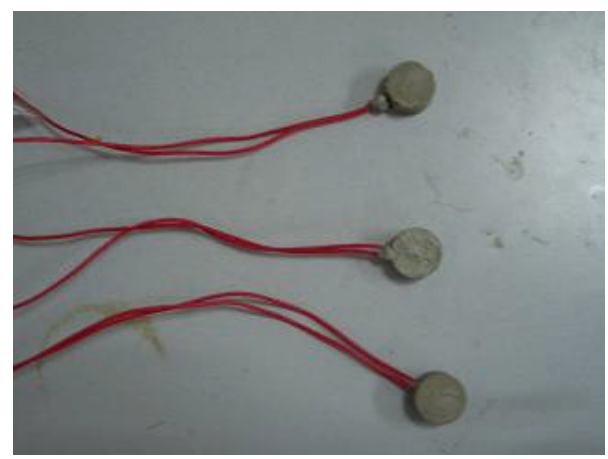

FIGURE 4: Embedded EMI active sensors.

the bridge consists of 70031 elements and 222962 nodes. There are 42148 SOLID65 elements, 5772 LINK8 elements, and 22111 MASS21 elements. According to the real conditions of the bridge, the piers are presumed to be fixed, and the two ends of girder are presumed to be supported by rolling bearings. The finite element models of the bridge and the prestressed steel strand are shown in Figures 7 and 8, respectively.
The modal analysis of the bridge model is carried out by using ANSYS, and the first six mode shapes of the bridge model are plotted, as shown in Figure 9. The first six natural frequencies and periods are also calculated and shown in Table 3. In order to verify the accurateness of the ANSYS model of the bridge, another finite element model of the bridge is established by using MIDAS. The modal analysis of the bridge model is also carried out by using MIDAS. The first six natural frequencies and periods of the bridge are also computed and listed in Table 3 for comparison. From Table 3 , it can be found that the maximal relative error of the first six natural frequencies computed by using ANSYS and MIDAS is $13.72 \%$ and the minimum is $1.46 \%$. This indicates that the finite element model established by using ANSYS is accurate.

4.2. Validation of Finite Element Model by Field Test. Based on the computed natural frequencies, we can select proper low frequency acceleration sensors for acquiring structural natural frequencies to further validate the finite element model of the bridge. According to the computed mode shapes, we can also select the proper arrangements of the acceleration sensors, keeping away from the nodes of mode shapes to 


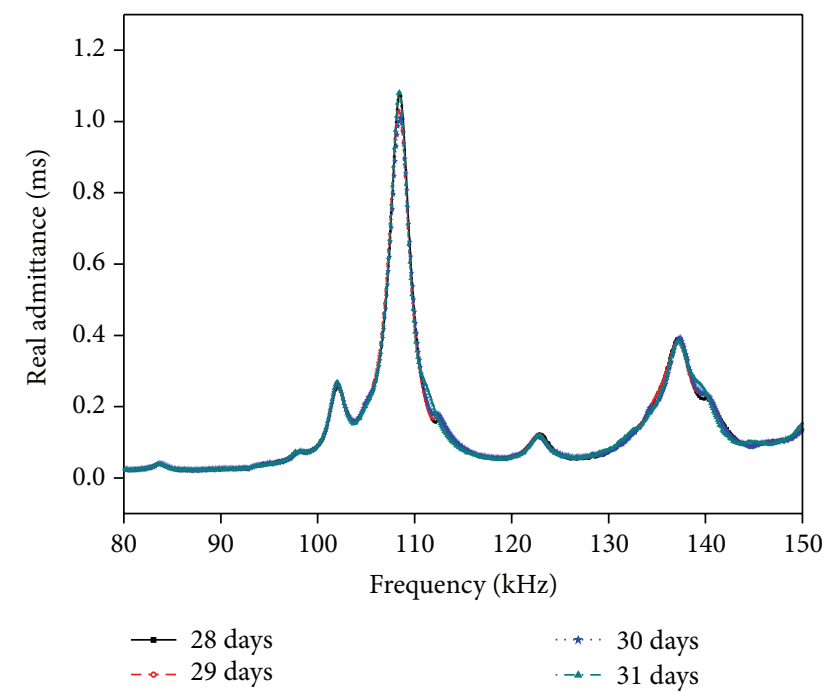

(a)

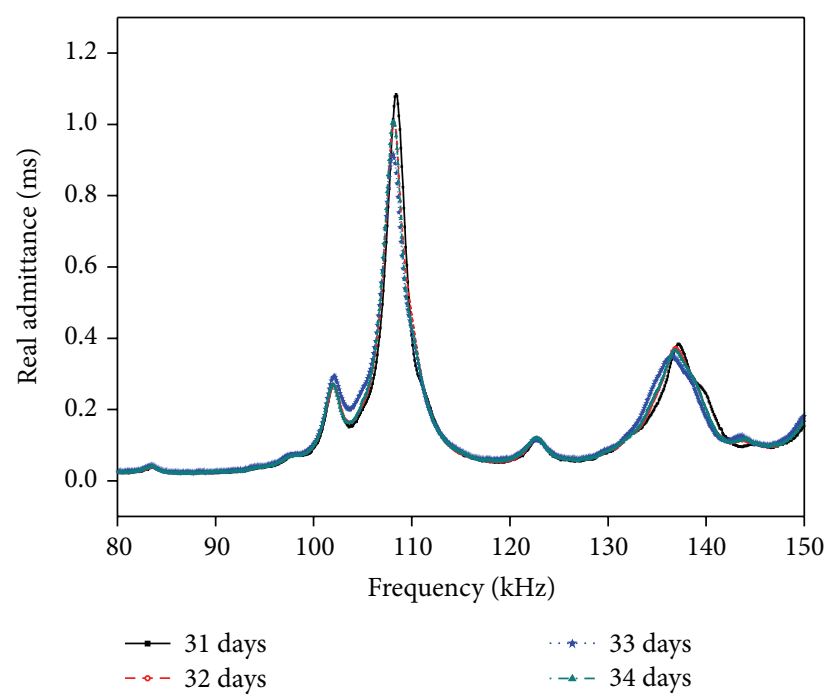

(b)

Figure 5: Real admittance curves of PZT impedance sensors encapsulated by using cement material: (a) 28-31 days and (b) 31-34 days.

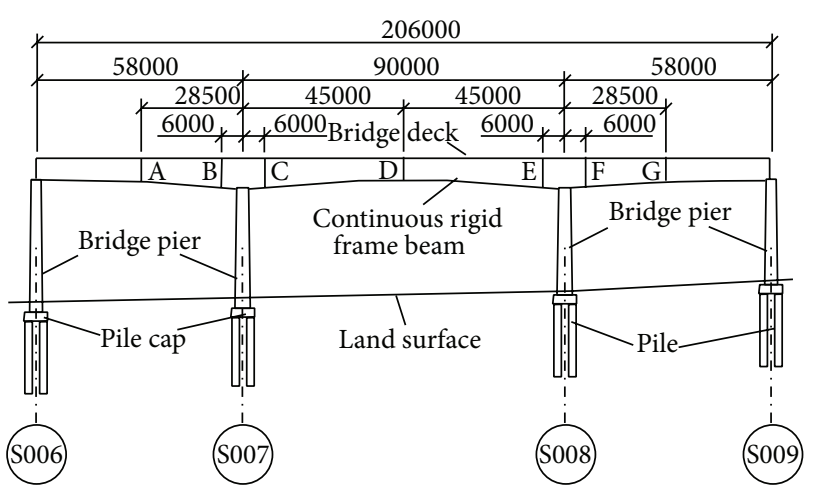

FIgURE 6: Continuous rigid-frame bridge model.

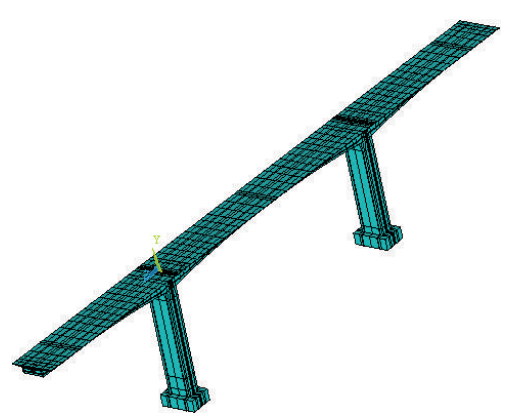

FIGURE 7: Finite element model of the continuous rigid-frame bridge.

be measured. In the field test, four CA-YD-109 acceleration sensors were selected for use, and the frequency range of the acceleration sensor is $0.2 \sim 500 \mathrm{~Hz}$. Therein, two acceleration sensors were installed at the edges of the midspan section in the span of S006-S007, respectively, and the other two were installed at the edges of the midspan section in the span of

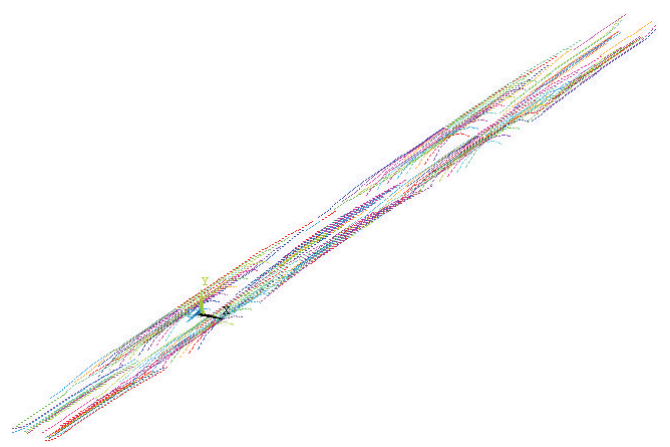

Figure 8: Finite element model of the prestressed steel strand.

S007-S008, respectively, as shown in Figure 10. The power spectrums of the acceleration responses in the spans of S006S007 and S007-S008 are obtained, respectively, as shown in Figures 11 and 12.

From Figures 11 and 12, it is found that the first antisymmetric transverse bending frequency is $0.93 \mathrm{~Hz}$ obtained by the modal tests in the span of S006-S007 and is $0.88 \mathrm{~Hz}$ in the span of S006-S007. The second symmetric vertical bending frequencies obtained by the modal tests are $1.91 \mathrm{~Hz}$ in both the spans of S006-S007 and S007-S008. The comparisons for natural frequencies between by finite element method and the field tests are also shown in Table 4. From Table 4, it is found that the computed natural frequencies are comparative to those obtained by the field tests, which further verify the accurateness of the finite element models of the bridge.

4.3. PZT and Strain Sensor Layouts and Field Tests. Seven critical cross sections labeled from A to G, as shown in Figure 6, are chosen for health monitoring. Only one typical section labeled as D will be discussed in this paper. Figure 13 presents the dimensions and details of this section. Ten 


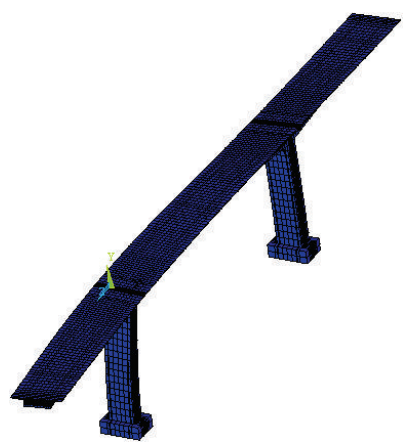

(a)

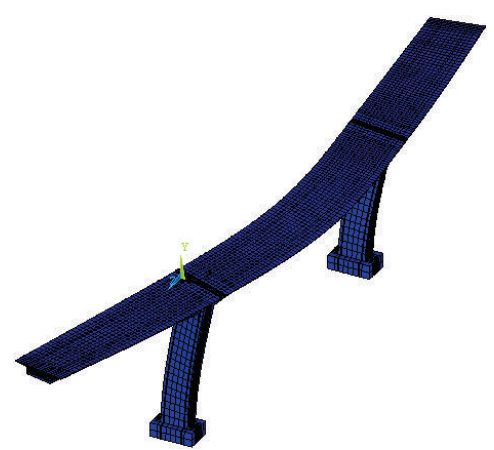

(d)

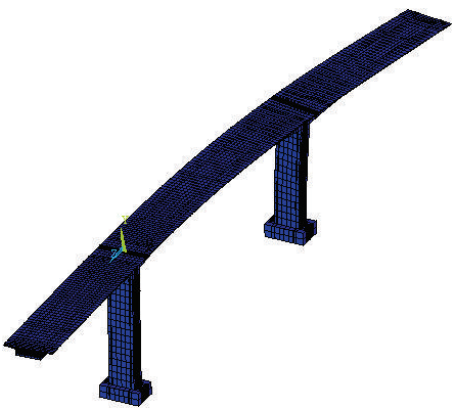

(b)

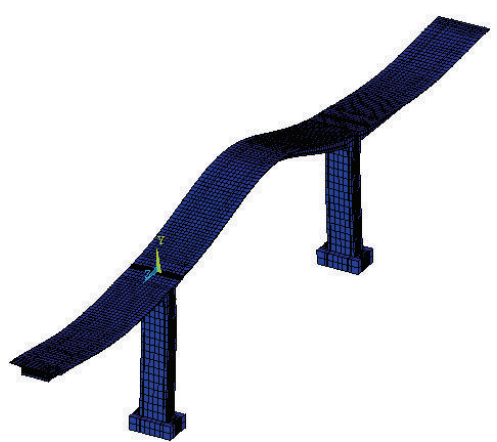

(e)

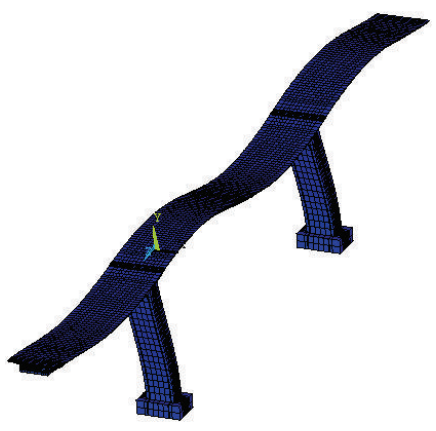

(c)

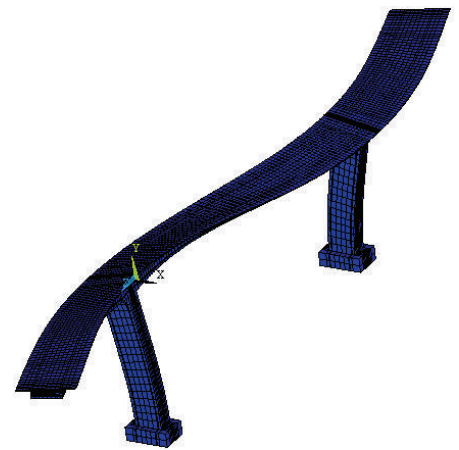

(f)

FIGURE 9: First six mode shapes of the continuous rigid-frame bridge: (a) first mode, (b) second mode, (c) third mode, (d) fourth mode, (e) fifth mode, and (f) sixth mode.

TABLE 3: Comparisons for natural frequencies and periods between ANSYS and MIDAS.

\begin{tabular}{|c|c|c|c|c|c|c|}
\hline \multirow{2}{*}{ Mode } & \multirow{2}{*}{ Mode types } & \multicolumn{2}{|c|}{ MIDAS } & \multicolumn{2}{|c|}{ ANSYS } & \multirow{2}{*}{$\Delta f(\%)$} \\
\hline & & Period & Frequency & Period & Frequency & \\
\hline 1 & $\begin{array}{l}\text { First antisymmetric } \\
\text { transverse bending }\end{array}$ & 1.177 & 0.85 & 1.15 & 0.87 & -2.36 \\
\hline 2 & $\begin{array}{l}\text { First symmetric } \\
\text { transverse bending }\end{array}$ & 1.172 & 0.853 & 1.031 & 0.97 & -13.72 \\
\hline 3 & $\begin{array}{l}\text { Second antisymmetric } \\
\text { vertical bending }\end{array}$ & 0.924 & 1.082 & 0.938 & 1.066 & 1.46 \\
\hline 4 & $\begin{array}{l}\text { Second symmetric } \\
\text { transverse bending }\end{array}$ & 0.751 & 1.332 & 0.74 & 1.351 & -1.46 \\
\hline 5 & $\begin{array}{l}\text { Second symmetric } \\
\text { vertical bending }\end{array}$ & 0.581 & 1.72 & 0.521 & 1.921 & -11.69 \\
\hline 6 & $\begin{array}{l}\text { Second antisymmetric } \\
\text { transverse bending }\end{array}$ & 0.394 & 2.54 & 0.366 & 2.734 & -7.62 \\
\hline
\end{tabular}

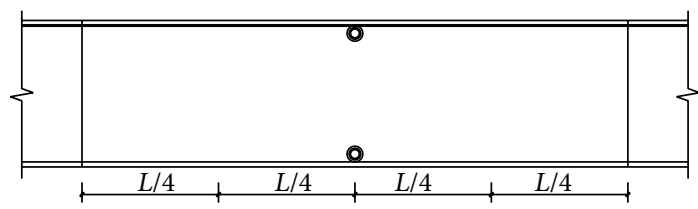

- Acceleration sensors

FIGURE 10: Arrangements of acceleration sensors in the spans of S006-S007 and S007-S008.
TABLE 4: Comparisons for natural frequencies between finite element method and the field tests.

\begin{tabular}{lcccc}
\hline \multirow{2}{*}{ Direction } & \multirow{2}{*}{ Span } & \multirow{2}{*}{ Experiment } & \multicolumn{2}{c}{ FEM } \\
& & & ANSYS & MIDAS \\
\hline \multirow{2}{*}{ Vertical } & S006-S007 & 1.91 & 1.92 & 1.72 \\
& S007-S008 & 1.91 & 1.92 & 1.72 \\
\hline \multirow{2}{*}{ Longitudinal } & S006-S007 & 0.93 & 0.87 & 0.85 \\
& S007-S008 & 0.88 & 0.87 & 0.85 \\
\hline
\end{tabular}




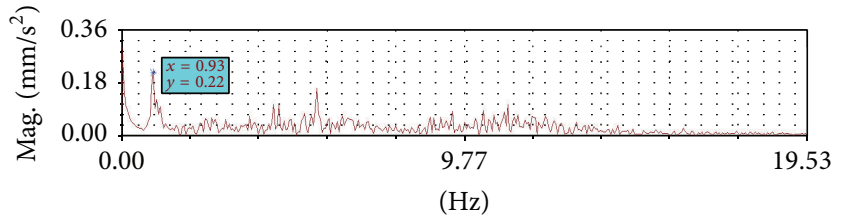

(a)

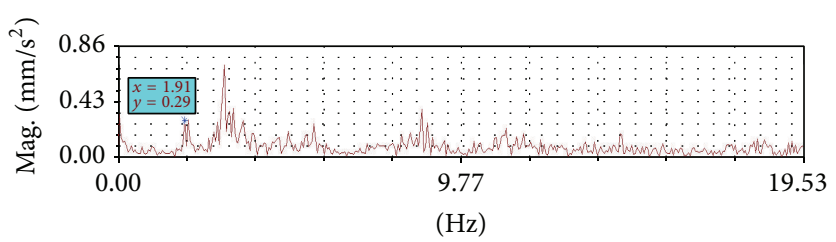

(b)

FIGURE 11: Power spectrums of the acceleration responses in the span of S006-S007: (a) longitudinal bridge direction and (b) vertical direction.

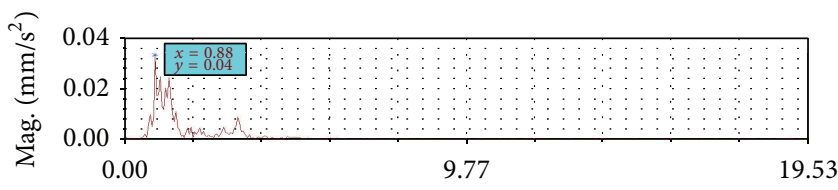

$(\mathrm{Hz})$

(a)

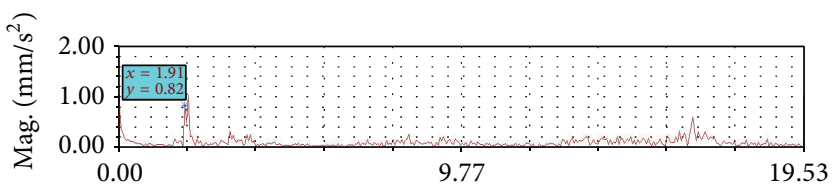

$(\mathrm{Hz})$

(b)

FIGURE 12: Power spectrums of the acceleration responses in the span of S007-S008: (a) longitudinal bridge direction and (b) vertical direction.

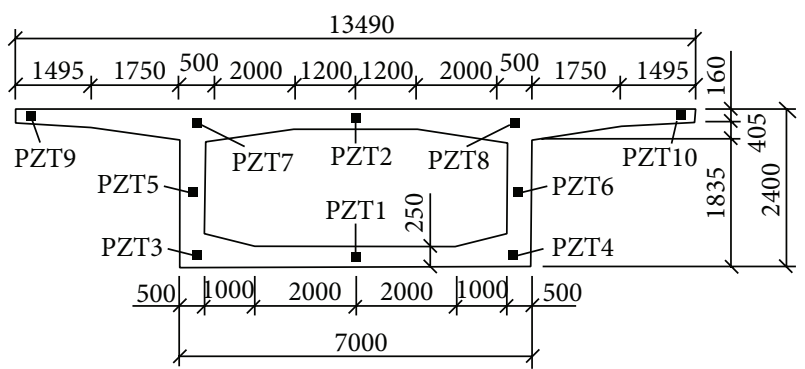

FIGURE 13: Arrangement of PZT sensors in section D.

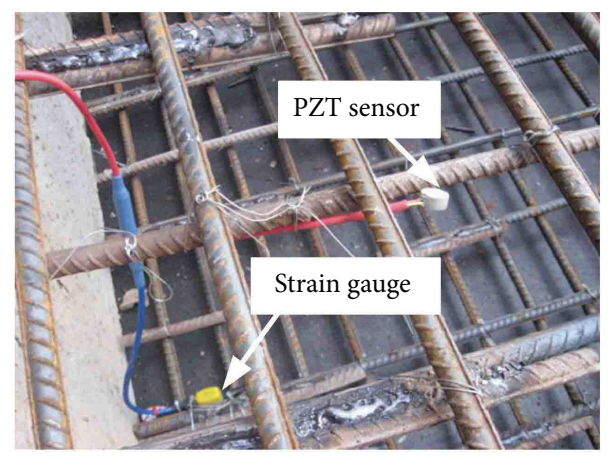

FIGURE 14: Arrangements of strain gauge and EMI active sensor.

EMI active sensors are embedded into section D of the continuous rigid-frame box beam prior to pouring concrete. The positions of these EMI sensors are shown in Figure 13. Ten intelligent digital strain sensors are also placed in the vicinity of corresponding EMI sensors, respectively. They were colligated at the bottom of rebar to measure the strains of concretes. The embedded EMI and strain sensors are shown in Figure 14. Figure 15 shows the protection of sensors from rough construction and wicked environment. In the test, the soldered wires connected to EMI transducers are

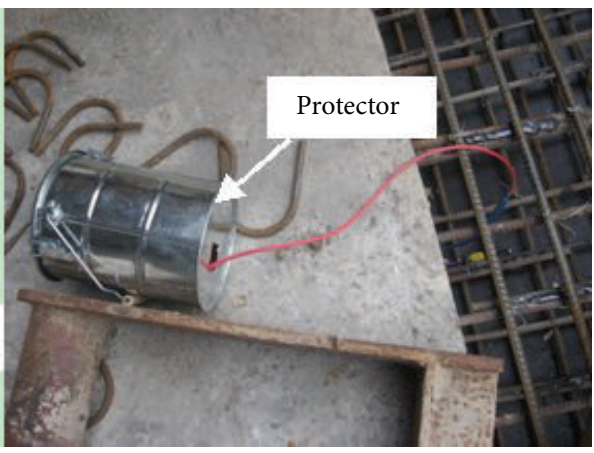

Figure 15: Protection of sensor.

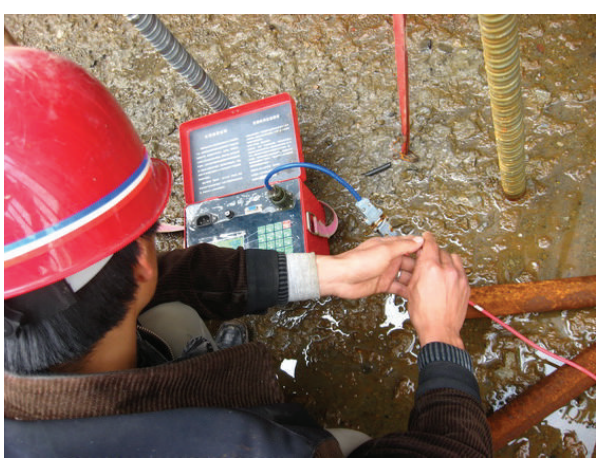

FIGURE 16: Field test.

then plugged into the impedance analyzer to acquire their admittance signatures. These strain gauges were interrogated automatically by a strain interrogator, as shown in Figure 16, respectively.

In order to ensure high sensitivity, high frequency excitation was used in this field test. It was suggested that a frequency range of $30 \mathrm{kHz}$ to $400 \mathrm{kHz}$ was suitable for health monitoring of concrete structures in the EMI-based method [14]. 


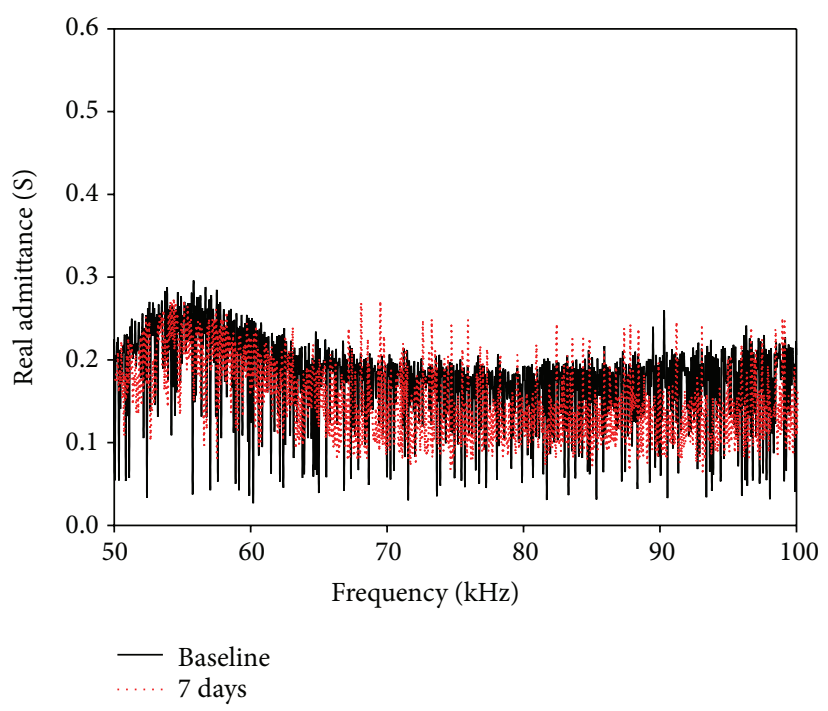

(a)

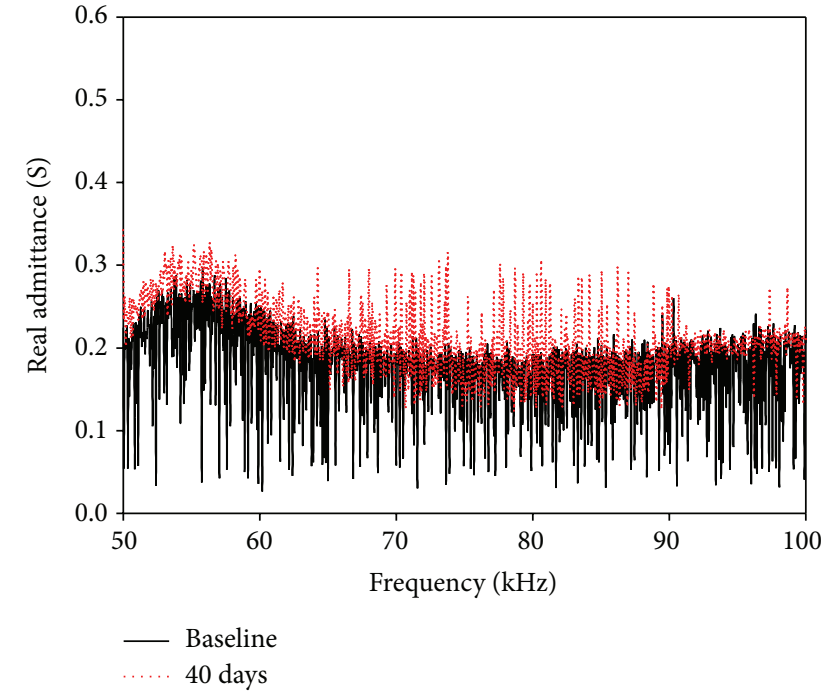

(b)

Figure 17: Real admittances of PZT1 in the frequency range of 50-100 kHz: (a) 7 days and (b) 40 days.

However, up to now, there is little analytical work done to determine the exact frequencies used in this method. In most of the studies, the range is determined by trial and error method. After a few trials, a frequency range of $50-100 \mathrm{kHz}$, having an interval of $50 \mathrm{~Hz}$, is selected in this study.

4.4. Test Results and Analysis. Health monitoring of the bridge has extended for more than four months. The real admittance signatures of all ten PZT sensors were obtained during construction and operation stages. Concretely, the field tests were carried out on days 1, 7, 14, 28, 40,60, and 120 after the concrete was poured. The strain values of concrete around PZT sensors were also measured at the same time. As described previously, the frequency range of $50-100 \mathrm{kHz}$ was selected when measuring EMI signatures. Figures 17(a) and 17(b) show the real admittance signatures of PZT1 in the frequency range of $50-100 \mathrm{kHz}$. The admittance measurements at the first day after the concrete was poured are considered as the baselines in this study. The baselines and the measurements at the seventh day are plotted in Figure 17(a), while the comparisons of the baselines and the fortieth-day measurements are shown in Figure 17(b). From Figure 17, it is found that the magnitudes and peak values of admittance signatures increase as time increases. In addition, it is also found that the admittance signatures appear to be very noisy, which should be due to the ambient noise in the construction field and the circuit noise of the PV70 impedance analyzer, which is used to measure EMI signatures in this study. However, it is difficult to quantitatively evaluate the health status of the bridge based only on the original admittance signatures. So, an assessment index needs to be introduced to quantify the variations of the admittance signatures.

Many kinds of assessment indexes have been developed to quantify the changes of admittance signatures in recent years, for instance, root-mean-square deviation (RMSD), mean absolute percentage deviation (MAPD), covariance (Cov), and correlation coefficient (CC) [17]. It is found that the RMSD and MAPD indexes are suitable for characterizing the location and the growth of damage. In this study, the RMSD index is employed. The RMSD is defined as

$$
\operatorname{RMSD}(\%)=\sqrt{\frac{\sum_{i=1}^{i=N}\left(y_{i}-x_{i}\right)^{2}}{\sum_{i=1}^{i=N} x_{i}{ }^{2}}} \times 100,
$$

where $x_{i}(i=1,2,3, \ldots, N)$ are baseline signatures obtained from the EMI sensors and $y_{i}(i=1,2,3, \ldots, N)$ are signatures at subsequent state with time increasing. The larger the difference between the baseline signature and the subsequent signature, the greater the RMSD value. The RMSD index quantifies the change of admittance signatures and hence evaluates the health status of structures quantitatively. Electrical admittance signatures are very convenient to acquire by the impedance analyzer in practice. Since the real part of admittance signatures shows more interaction with the structure than the imaginary part of conductance [26], the real part of admittance signature instead of impedance signature is adopted in this study.

Figure 18(a) presents the RMSD values of PZT1 measured in different times, while Figure 18(b) shows corresponding strain measurements of concrete around PZT1. It is observed that both the RMSD values and the strains have the same change trend. As we know, in the stage of construction (the first 28 days), the bottom of continuous rigid-frame box girder is subjected to tension under the gravity of concrete, which is proved in Figure 18(b). The tensile strain of concrete decreased due to the interaction of shrinkage and hardening behaviors. The decline process of tensile strain is also clearly observed in Figure 18(b). Consequently, the RMSD value of PZT1 will decrease in construction stage as shown in Figure 18(a). The changes of RMSD values and strains in 


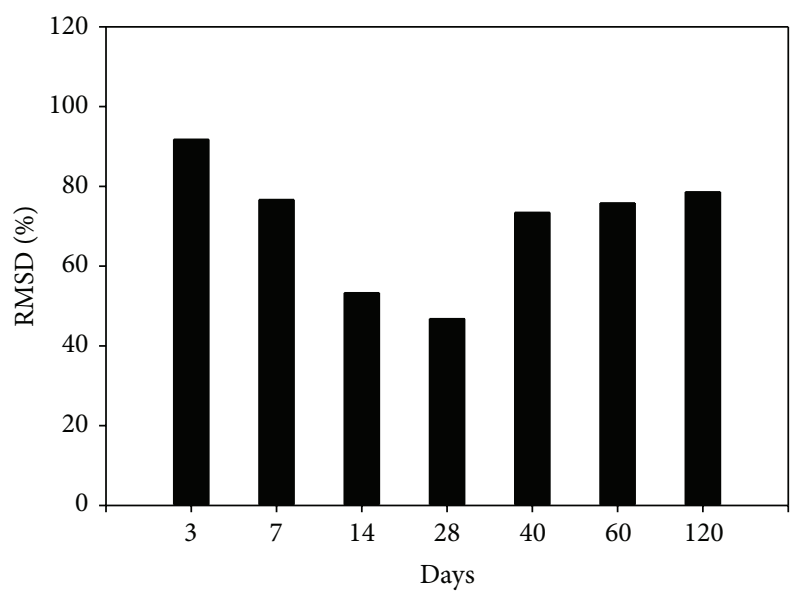

(a)

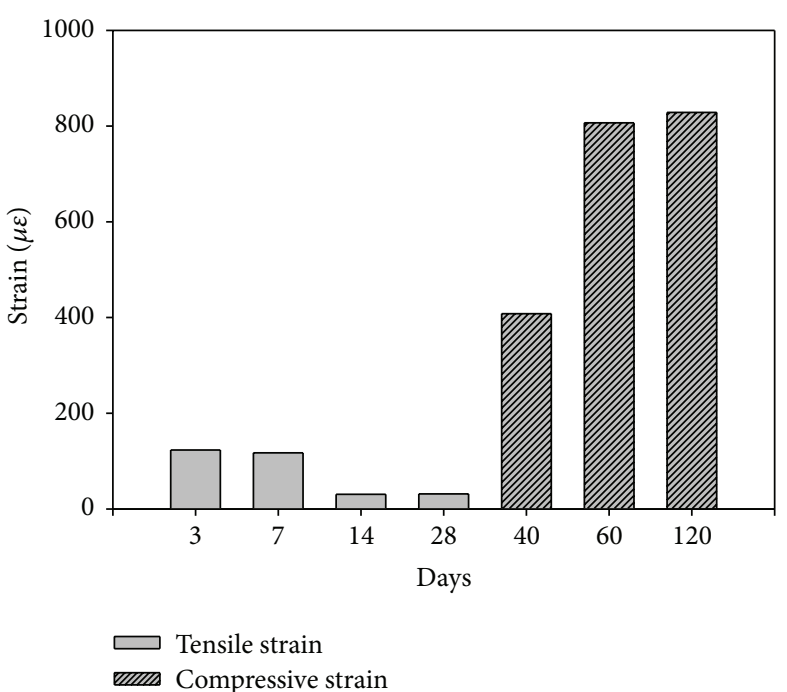

(b)

FIGURE 18: Measurements for PZT1: (a) RMSD value and (b) strain of concrete around EMI sensor.

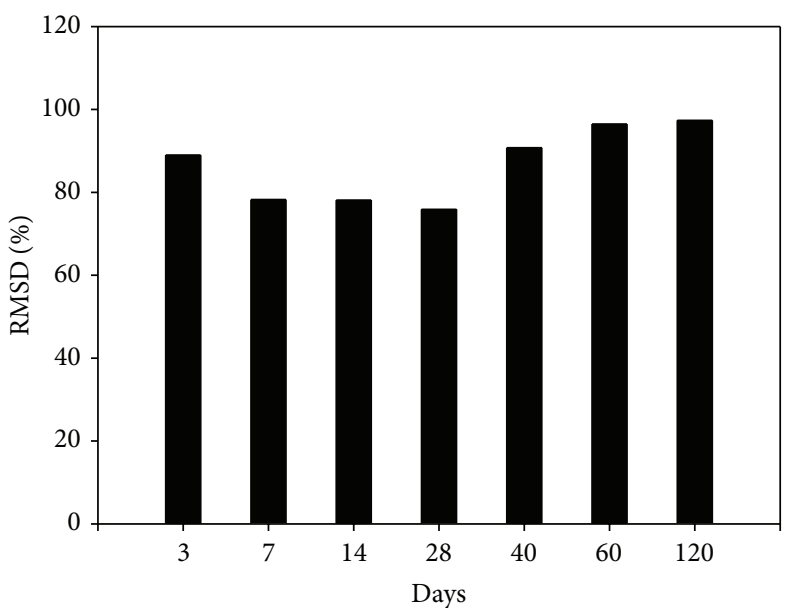

(a)

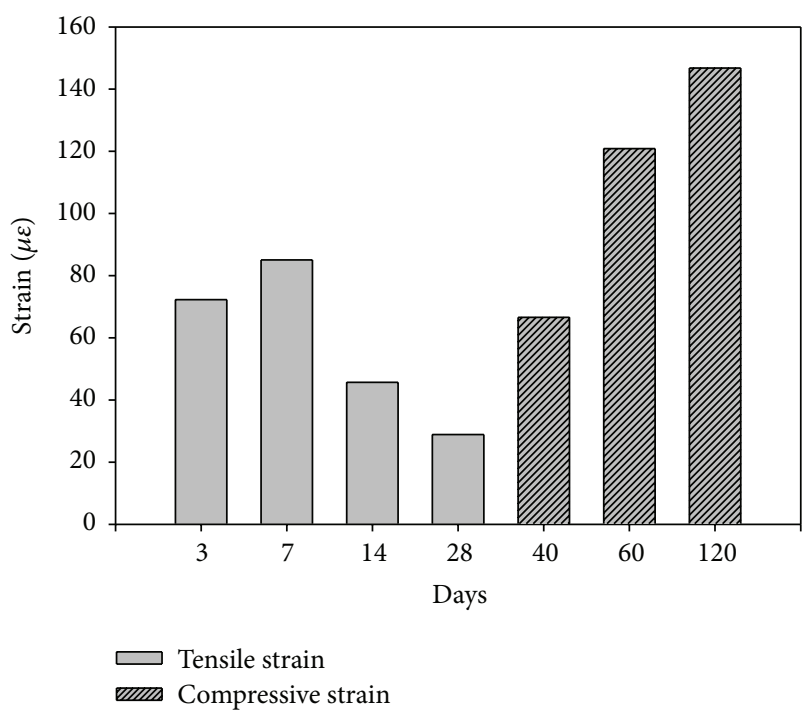

(b)

FIgURE 19: Measurements for PZT2: (a) RMSD value and (b) strain of concrete around EMI sensor.

the stage of operation are also presented in Figures 18(a) and 18(b), respectively. Both RMSD value and strain increase greatly in this stage. Since formworks were dismantled 40 days after the concrete was poured, the bottom of the box girder was subjected to compression rather than tension. The compressive strain increased greatly soon after formworks were dismantled and then grew slowly with time. Similar results can be obtained for PZT2 as shown in Figure 19. The results suggest that the trend of RMSD change is well consistent with the strain of concrete.

The RMSD values of PZT3 and PZT4 are computed and shown in Figure 20(a). Figure 20(b) presents the strain values of concretes where PZT3 and PZT4 are symmetrically arranged. Because of the symmetry of the position, the theoretical strains of the concretes around the two EMI sensors should be the same. This is well proved by the strain measurements, as shown in Figure 20(b). Just as the strain measurements, the RMSD values were slightly different but approximately identical for both two EMI sensors. The differences were due to some factors, such as the construction error of concrete structure, the position error of sensors, and the parameter discrepancy of different sensors. The same variation trends of RMSD and strain in the stages of construction and operation are also found in Figure 20. The strains and RMSD values of PZT5, PZT6, PZT7, PZT8, PZT9, and PZT10 are plotted in Figures 21-23, respectively. It is also 


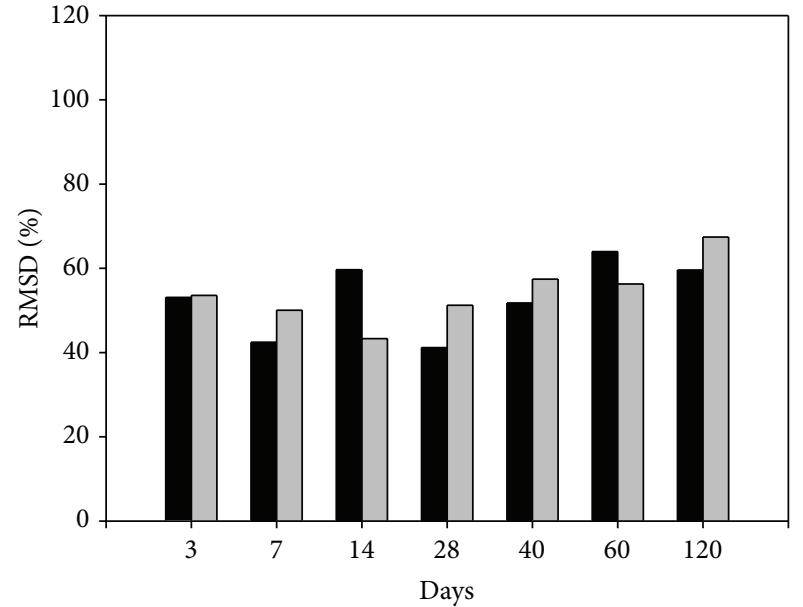

PZT3

$\rightleftarrows$ PZT4

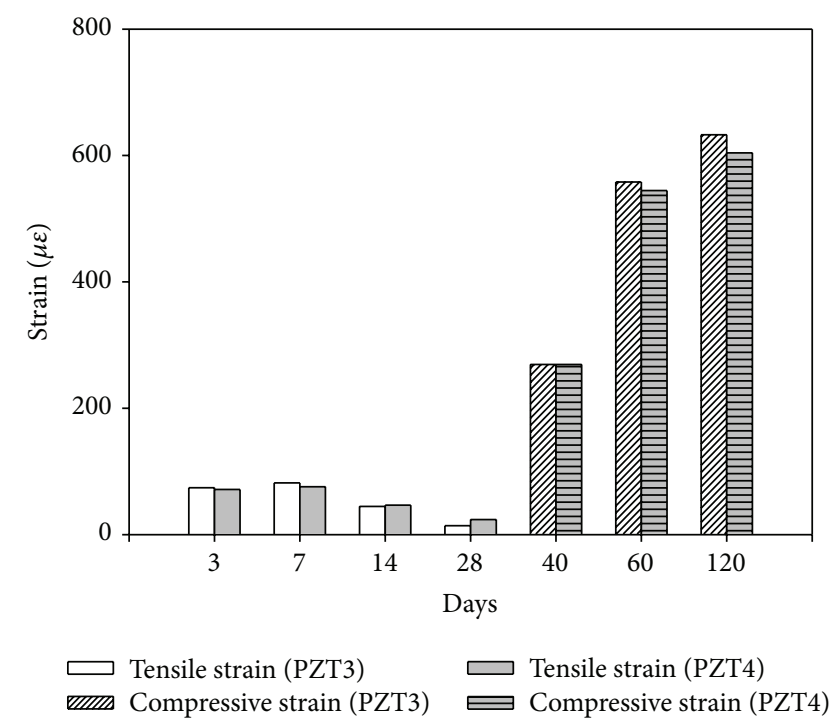

(b)

FIGURE 20: Comparison of PZT3 and PZT4: (a) RMSD value and (b) strain of concrete around EMI sensors.

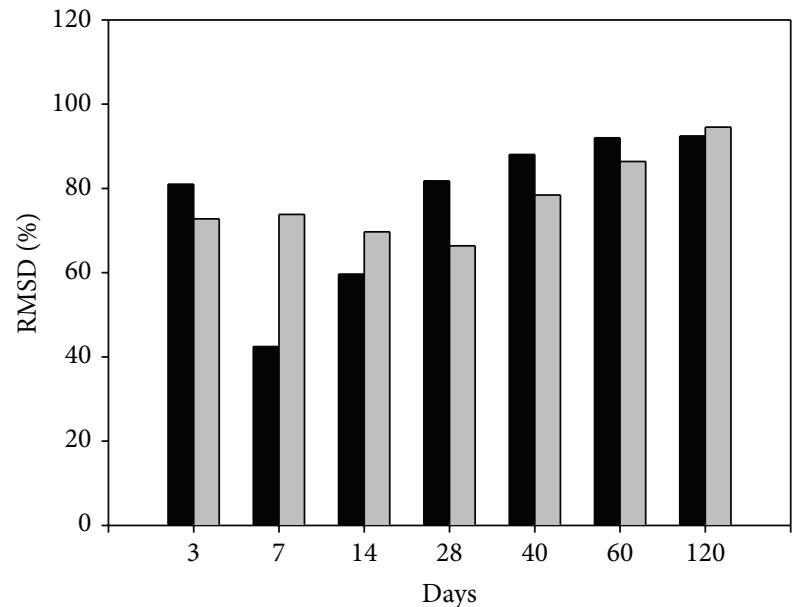

PZT5 $\varpi$ PZT6

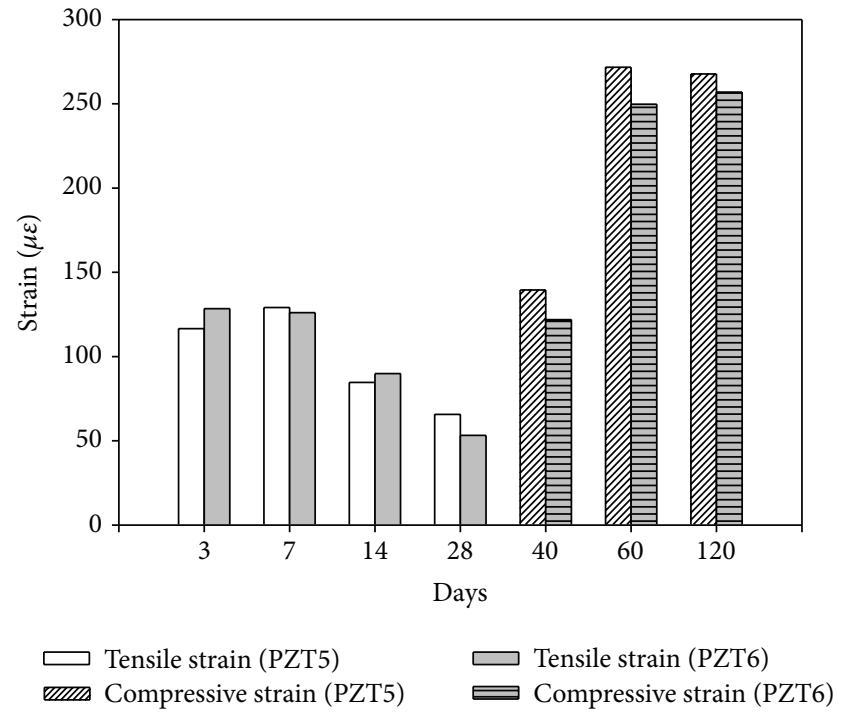

(b)

FIgURE 21: Comparison of PZT5 and PZT6: (a) RMSD value and (b) strain of concrete around EMI sensors.

observed from these figures that the RMSD values are correlated well with the corresponding concrete strains and both of them have the same change trends in different periods. All these figures indicate that, based on the RMSD values of EMI sensors and the strain measurements of concrete around them, the health status of the bridge in construction and operation process is monitored and evaluated successfully.

\section{Conclusions}

Health monitoring of a continuous rigid-frame bridge is studied based on embedded EMI and strain sensors in this paper. The embedded EMI active sensors are designed and fabricated using PZT patches. It is found that asphalt lacquer can be used as waterproof material of PZT sensors, and Portland cement is also one of promising encapsulation materials of PZT sensors. Finite element modeling and modal analysis of the continuous rigid-frame bridge are also implemented. The analysis results indicate the computed natural frequencies by using ANSYS and MIDAS are comparable to those obtained by the field tests. In this study, in order to ensure high sensitivity of embedded EMI sensors to small changes in concrete structures, high frequency excitation is selected when EMI technique is used. It is found that the frequency range of $50-100 \mathrm{kHz}$ was suitable for health monitoring of the large-scale concrete bridge. It is also found that the changes 

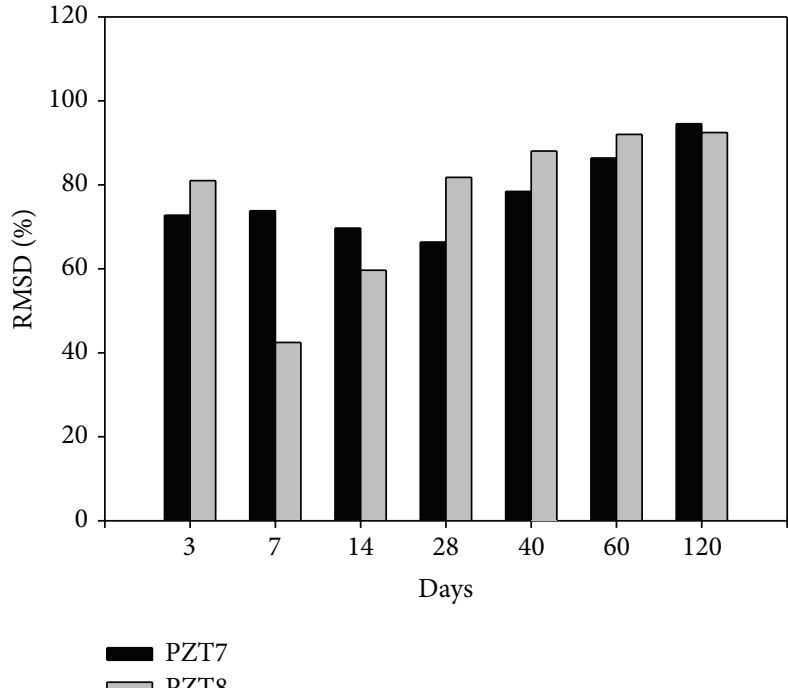

$\square$ PZT8

(a)

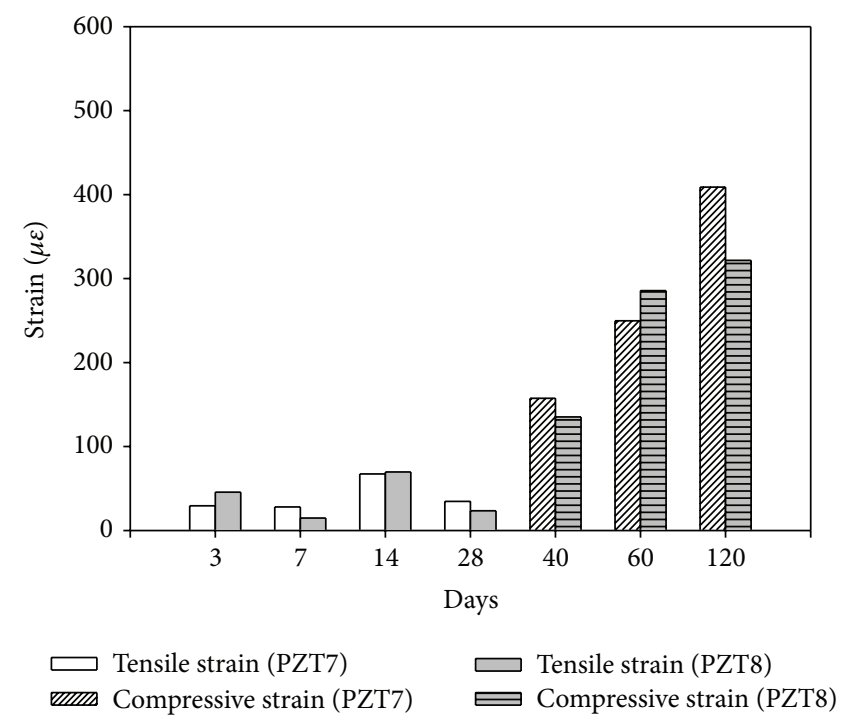

(b)

FIgURE 22: Comparison of PZT7 and PZT8: (a) RMSD value and (b) strain of concrete around EMI sensors.

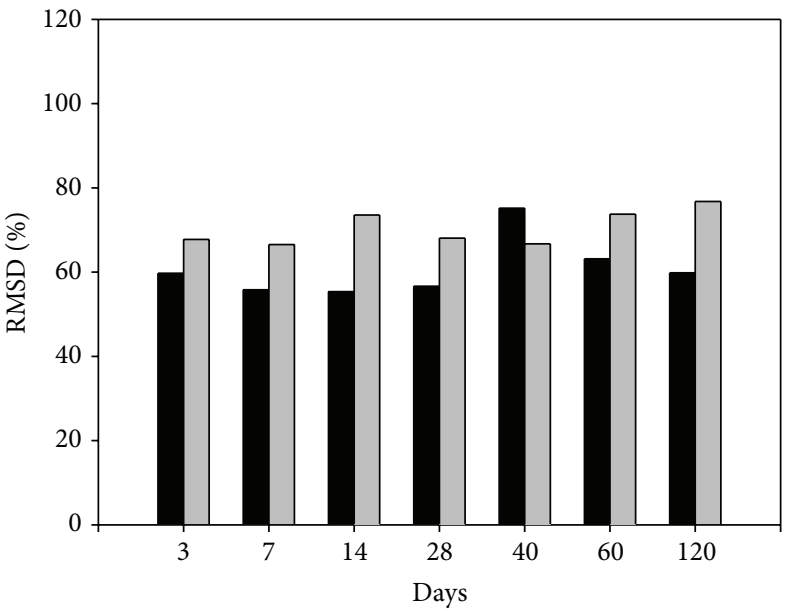

PZT9

ए PZT10

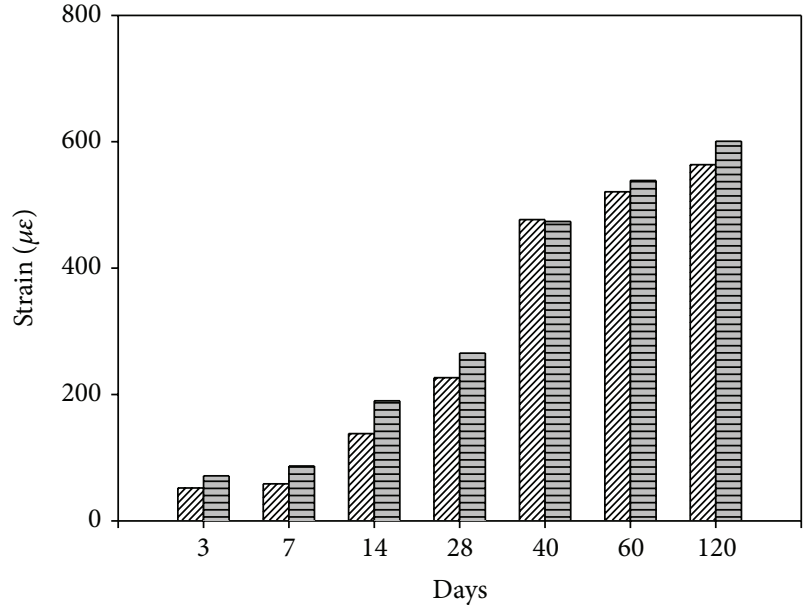

שm Compressive strain (PZT9)

$\rightleftharpoons$ Compressive strain (PZT10)

(b)

Figure 23: Comparison of PZT9 and PZT10: (a) RMSD value and (b) strain of concrete around EMI sensors.

in RMSD values of EMI measurements show similar trends to the strain measurements at the same positions. It could be concluded that the RMSD is a suitable assessment index for health monitoring of large-scale concrete bridges. Based on the obtained electrical admittance and strain measurements, the health statuses of the continuous rigid-frame bridge in the construction and operation stages are monitored and evaluated successfully.

\section{Conflict of Interests}

The authors declare that there is no conflict of interests regarding the publication of this paper.

\section{Acknowledgments}

The authors would like to extend their thanks to the joint financial support by National Natural Science Fund of China (51278215), National Basic Research Program of China (973 Program: 2011CB013800), and the Fundamental Research Funds for the Central Universities (HUST: 2014QN211).

\section{References}

[1] S. W. Doebling, C. R. Farrar, and M. B. Prime, "A summary review of vibration-based damage identification methods," Shock and Vibration Digest, vol. 30, no. 2, pp. 91-105, 1998. 
[2] K. P. Chong, N. J. Carino, and G. Washer, "Health monitoring of civil infrastructures," Smart Materials and Structures, vol. 12, no. 3, pp. 483-493, 2003.

[3] J. P. Ou and H. Li, "Structural health monitoring in mainland China: review and future trends," Structural Health Monitoring, vol. 9, no. 3, pp. 219-231, 2010.

[4] L. R. Zhou, G. R. Yan, L. Wang, and J. Ou, "Review of benchmark studies and guidelines for structural health monitoring," Advances in Structural Engineering, vol. 16, no. 7, pp. 1187-1206, 2013.

[5] S. Bhalla and C. K. Soh, "High frequency piezoelectric signatures for diagnosis of seismic/blast induced structural damages," NDT \& E International, vol. 37, no. 1, pp. 23-33, 2004.

[6] B. Zhang, B. Benmokrane, J.-F. Nicole, and R. Masmoudi, "Evaluation of fibre optic sensors for structural condition monitoring," Materials and Structures, vol. 35, no. 250, pp. 357364, 2002.

[7] W. Zhang, J. Q. Gao, B. Shi, H. Cui, and H. Zhu, "Health monitoring of rehabilitated concrete bridges using distributed optical fiber sensing," Computer-Aided Civil and Infrastructure Engineering, vol. 21, no. 6, pp. 411-424, 2006.

[8] S. Laflamme, M. Kollosche, V. D. Kollipara, H. S. Saleem, and G. Kofod, "Large-scale surface strain gauge for health monitoring of civil structures," in Nondestructive Characterization for Composite Materials, Aerospace Engineering, Civil Infrastructure, and Homeland Security, vol. 8347 of Proceedings of SPIE, International Society for Optical Engineering, San Diego, Calif, USA, April 2012.

[9] C. I. Merzbacher, A. D. Kersey, and E. J. Friebele, "Fiber optic sensors in concrete structures: a review," Smart Materials and Structures, vol. 5, no. 2, pp. 196-208, 1996.

[10] H.-N. Li, D.-S. Li, and G.-B. Song, "Recent applications of fiber optic sensors to health monitoring in civil engineering," Engineering Structures, vol. 26, no. 11, pp. 1647-1657, 2004.

[11] K. S. C. Kuang, S. T. Quek, C. G. Koh, W. J. Cantwell, and P. J. Scully, "Plastic optical fibre sensors for structural health monitoring: a review of recent progress," Journal of Sensors, vol. 2009, Article ID 312053, 13 pages, 2009.

[12] G. Park, H. H. Cudney, and D. J. Inman, "Impedance-based health monitoring of civil structural components," Journal of Infrastructure Systems, vol. 6, no. 4, pp. 153-160, 2000.

[13] K. K.-H. Tseng and A. S. K. Naidu, "Non-parametric damage detection and characterization using smart piezoceramic material," Smart Materials and Structures, vol. 11, no. 3, pp. 317-329, 2002.

[14] G. Park, H. Sohn, C. R. Farrar, and D. J. Inman, "Overview of piezoelectric impedance-based health monitoring and path forward," Shock and Vibration Digest, vol. 35, no. 6, pp. 451-463, 2003.

[15] C. K. Soh, K. K.-H. Tseng, S. Bhalla, and A. Gupta, "Performance of smart piezoceramic patches in health monitoring of a RC bridge," Smart Materials and Structures, vol. 9, no. 4, pp. 533-542, 2000.

[16] S. W. Shin and T. K. Oh, "Application of electro-mechanical impedance sensing technique for online monitoring of strength development in concrete using smart PZT patches," Construction and Building Materials, vol. 23, no. 2, pp. 1185-1188, 2009.

[17] D. S. Wang and H. P. Zhu, "Monitoring of the strength gain of concrete using embedded PZT impedance transducer," Construction and Building Materials, vol. 25, no. 9, pp. 37033708, 2011.
[18] D. Wang, H. Song, and H. Zhu, "Numerical and experimental studies on damage detection of a concrete beam based on PZT admittances and correlation coefficient," Construction and Building Materials, vol. 49, pp. 564-574, 2013.

[19] D. S. Wang, H. Y. Song, and H. P. Zhu, "Embedded 3D electromechanical impedance model for strength monitoring of concrete using a PZT transducer," Smart Materials and Structures, vol. 23, no. 11, Article ID 115019, 2014.

[20] X. Y. Hu, H. P. Zhu, and D. S. Wang, "A study of concrete slab damage detection based on the electromechanical impedance method," Sensors, vol. 14, no. 10, pp. 19897-19909, 2014.

[21] J. T. Kim, J. H. Park, D. S. Hong, H. M. Cho, W. B. Na, and J. H. Yi, "Vibration and impedance monitoring for prestress-loss prediction in PSC girder bridges," Smart Structures and Systems, vol. 5, no. 1, pp. 81-94, 2009.

[22] D. S. Hong, H. J. Jung, and J. T. Kim, "Hybrid damage monitoring of steel plate-girder bridge under train-induced excitation by parallel accelerationimpedance approach," Structural Engineering and Mechanics, vol. 40, no. 5, pp. 719-743, 2011.

[23] H. Song, H. J. Lim, and H. Sohn, "Electromechanical impedance measurement from large structures using a dual piezoelectric transducer," Journal of Sound and Vibration, vol. 332, no. 25, pp. 6580-6595, 2013.

[24] E. F. Crawley and E. H. Anderson, "Detailed models of piezoelectric actuation of beams," Journal of Intelligent Material Systems and Structures, vol. 1, no. 1, pp. 4-25, 1990.

[25] C. Liang, F. P. Sun, and C. A. Rogers, "Coupled electro-mechanical analysis of adaptive material systems-determination of the actuator power consumption and system energy transfer," Journal of Intelligent Material Systems and Structures, vol. 5, no. 1, pp. 12-20, 1994.

[26] F. P. Sun, Z. Chaudhry, C. Liang, and C. A. Rogers, "Truss structure integrity identification using PZT sensor-actuator," Journal of Intelligent Material Systems and Structures, vol. 6, no. 1, pp. 134-139, 1995. 

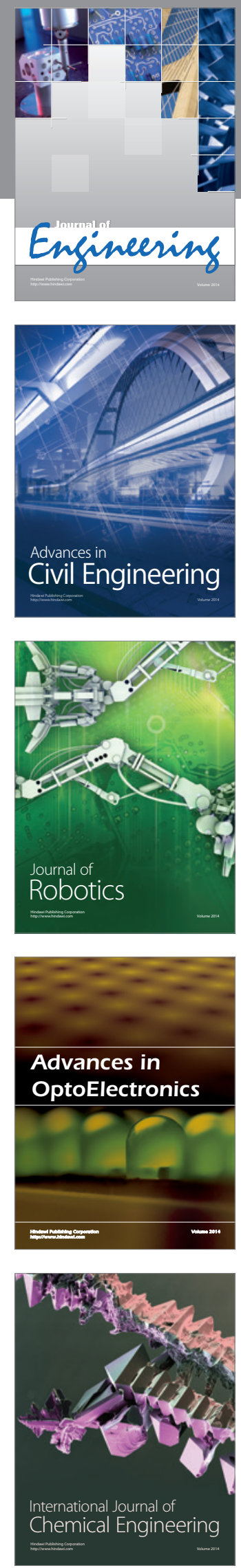

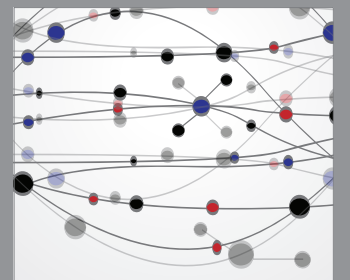

The Scientific World Journal
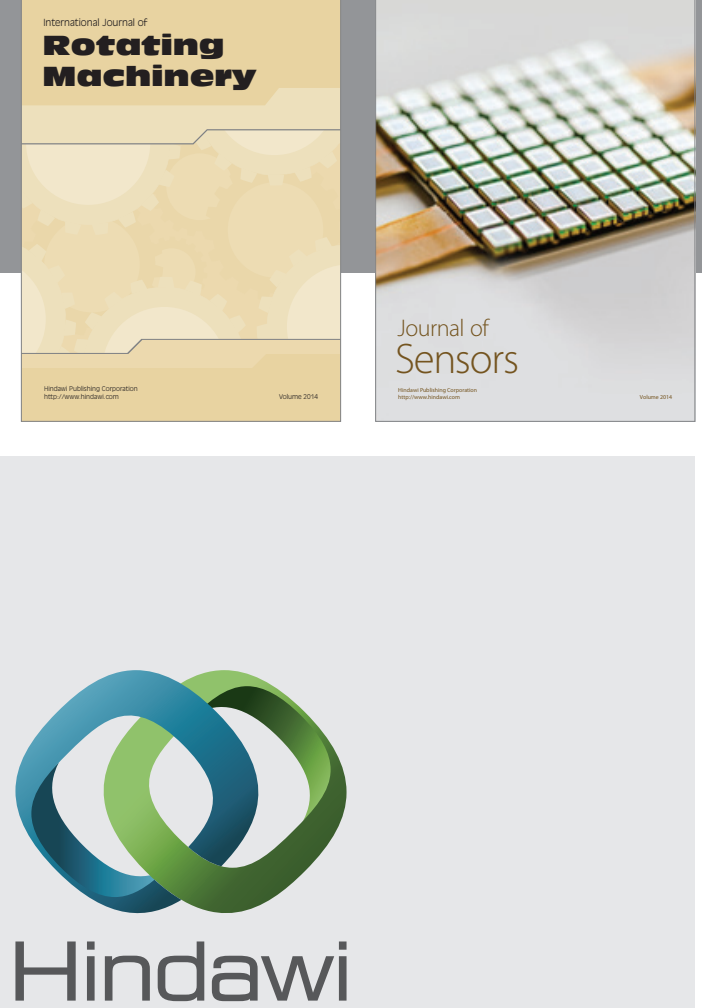

Submit your manuscripts at http://www.hindawi.com
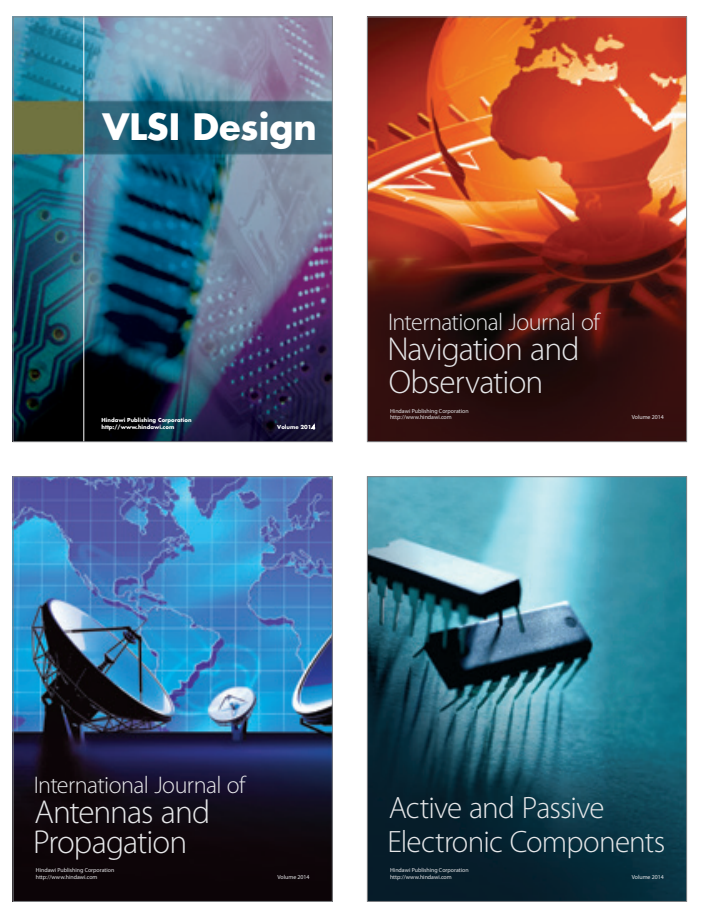
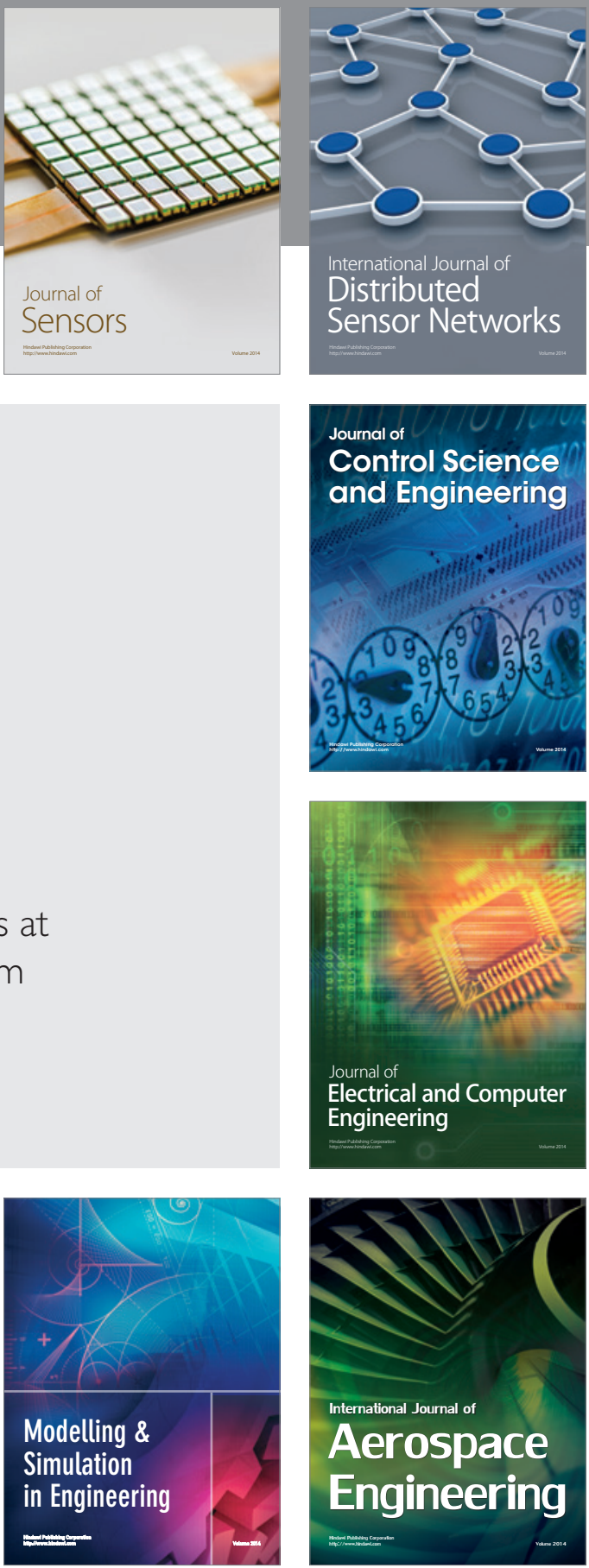

Journal of

Control Science

and Engineering
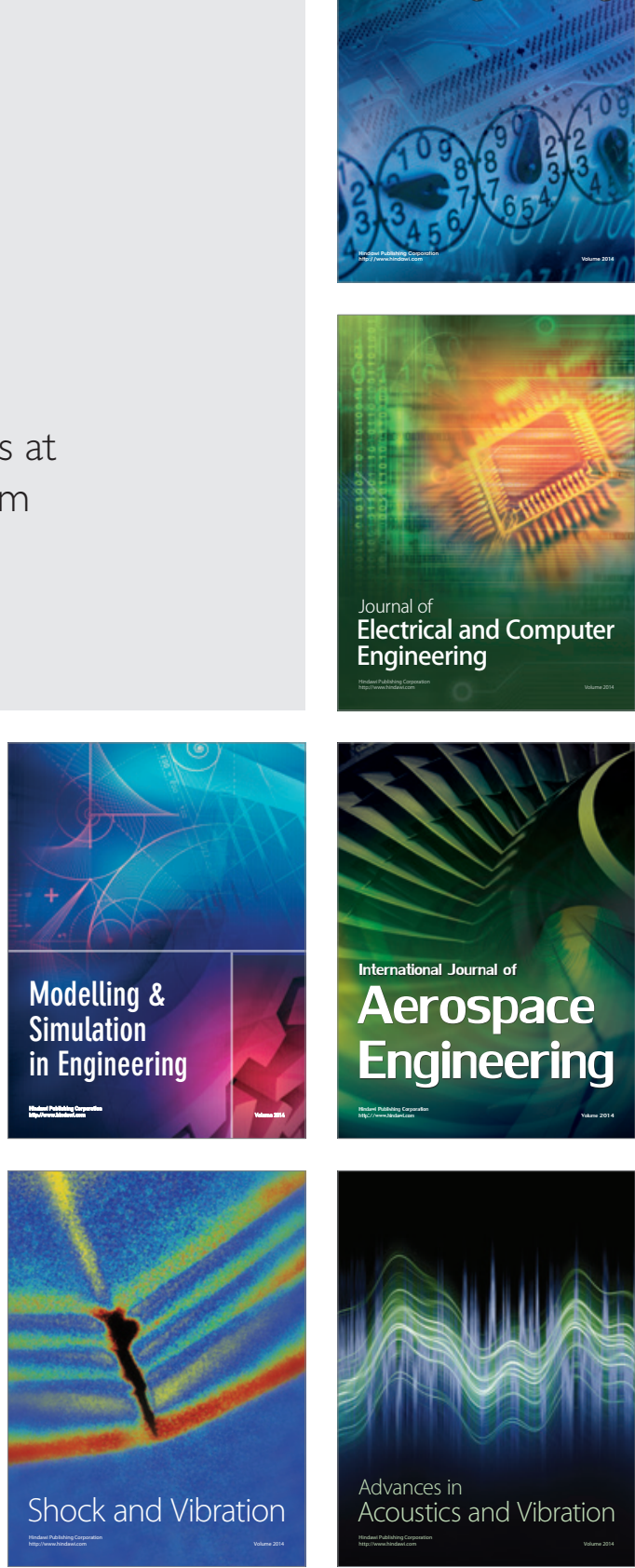